Research Paper

\title{
Clinical Outcome of Small Renal Cell Carcinoma after Delayed Surgery versus Immediate Surgery
} \author{
Nishioka2 ${ }^{2}$ Atsunobu Esa ${ }^{5}$, Hiroshi Kajikawa ${ }^{6}$ and Hirotsugu Uemura ${ }^{1}$ \\ 1. Department of Urology, Kinki University Faculty of Medicine, Osaka-Sayama, Osaka, Japan; \\ 2. Department of Urology, Sakai Hospital Kinki University Faculty of Medicine, Sakai, Osaka, Japan; \\ 3. Department of Urology, Mimihara General Hospital, Sakai, Osaka, Japan; \\ 4. Department of Urology, Saiseikai Tondabayashi Hospital, Tondabayashi, Osaka, Japan; \\ 5. Department of Urology, NTT West Osaka Hospital, Osaka, Osaka, Japan; \\ 6. Department of Urology, Izumiotsu Municipal Hospital, Izumiotsu, Osaka, Japan.
}

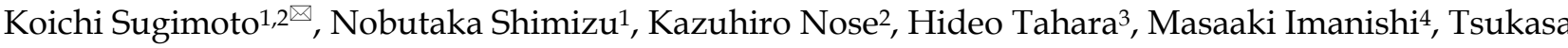

$\square$ Corresponding author: Koichi Sugimoto, M.D. sugimoto@sakai.med.kindai.ac.jp. Department of Urology, Kinki University Faculty of Medicine. 377-2 Ohno-Higashi, Osaka-Sayama, Osaka 589-8511, Japan.

( ) Ivyspring International Publisher. This is an open-access article distributed under the terms of the Creative Commons License (http://creativecommons.org/ licenses/by-nc-nd/3.0/). Reproduction is permitted for personal, noncommercial use, provided that the article is in whole, unmodified, and properly cited.

Received: 2013.06.19; Accepted: 2013.07.05; Published: 2013.07.19

\begin{abstract}
Background: This study was undertaken to investigate the growth rate and clinical outcome of patients with a small renal mass (SRM) after delayed surgery versus immediate surgery.

Methods: We reviewed the clinical records of 328 patients with SRM $\leqq 4 \mathrm{~cm}$ at diagnosis, who underwent delayed or immediate surgical intervention from January 2000 to December $201 \mathrm{I}$. Radiographic evaluation using CT scan and MRI were performed at least every 6 months and the tumor size was determined at least twice in the delayed surgery group.

Results: A total of 292 RCC patients with PT IaNOMO were identified; among them, 32 patients had been managed with delayed surgery intervention. No statistically significant difference was observed in overall survival rate (OSR) and cancer recurrence-free rate (CRFR). But cancer-specific survival rate (CSSR) was significantly lower in the delayed surgery group $(p=0.0002)$.

Conclusions: The overall survival rate of delayed surgery was not inferior compared with that after immediate surgery. Delayed surgery intervention for SRMs is a treatment option in the current study.
\end{abstract}

Key words: renal cell carcinoma, small renal mass, delayed surgery, immediate surgery, natural history.

\section{Introduction}

Small renal masses (SRMs) have been increasingly detected using noninvasive abdominal imaging techniques, such as ultrasonography (US), computed tomography (CT) and magnetic resonance imaging (MRI). ${ }^{1-5}$

A retrospective review has revealed that most SRMs show a slow growth rate and low malignant potential. ${ }^{6}$ Metastasis may occur in $7 \%$ of patients with small renal cell carcinoma. ${ }^{7}$

A significant number of SRMs are diagnosed as incidental tumors, often in elderly patients. As life expectancy continues to improve, the number of patients with incidentally detected renal masses is likely to increase further, as will the number of patients being offered surgical intervention. There is increasing evidence to suggest that surgical intervention may not be needed in all SRMs. ${ }^{8}$

Therefore, delayed surgery may be a treatment option for SRMs. This study was a retrospective evaluation of the treatment efficacy of delayed surgery compared with immediate surgery. 


\section{Methods}

The clinical records of 328 patients with 338 detected SRMs $\leqq 4 \mathrm{~cm}$ were retrospectively reviewed at Kinki University Faculty of Medicine and affiliated hospital from January 2000 to December 2011. All patients had undergone surgical interventions. The choice of treatment was based on tumor characteristics, patients factors, including age and overall survival risk. We only included patients with cT1aNOM0 SRMs managed by delayed or immediate interventions. Routine percutaneous renal biopsy of cT1a lesions was not performed.

Clinical and pathological stages were determined using the 2009 American Joint Committee on Cancer / International Union Against Cancer TNM guidelines. ${ }^{9}$ After surgery, the patients were followed up every 3-6 months.

Survival curves were estimated using the Kaplan-Meier method. Non-parametric MannWhitney $U$-test and $\chi^{2}$ test were used in statistical analyses.

\section{Results}

The mean age of the 328 patients was 63.7 years (range: 26-86). There were 225 men (68.6\%) and 103 women (31.4\%). Histopathological analysis revealed that 313 masses (92.6\%) were malignant (Table 1). A total of 299 patients had RCC: pT1a in 292 patients and $\mathrm{pT} 3$ in 7 patients.

The mean age in the delayed surgery group was 64.3 years (range: $35-80$ ). The mean age in the immediate surgery group was 63.7 years (range: 30-86). There were 25 men and 7 women in the delayed sur- gery group. There were 187 men and 73 women in the immediate surgery group. Ten patients underwent radical nephrectomy and 22 patients underwent partial nephrectomy in the delayed surgery group. In the immediate surgery group, 161 patients underwent radical nephrectomy and 100 patients underwent partial nephrectomy. Of the 32 patients in the delayed surgery group, 27 had clear cell carcinoma. Of the 260 patients in the immediate surgery group, 231 had clear cell carcinoma. The mean postoperative follow up time was 39.7 months in the delayed surgery, and 51.1 months in the immediate surgery group. Only operation methods was significantly different between them $(p=0.0012)$ (Table 2$)$. Only one patient had bilateral RCC.

Table I. Clinicopathological characteristics of 328 patients with 338 SRMs.

\begin{tabular}{lc}
\hline Characteristic & Number of masses (\%) \\
\hline Histology & $313(92.6)$ \\
Malignancy & $264(78.1)$ \\
Clear cell & $25(7.4)$ \\
Papillary & $6(1.8)$ \\
Chromoph obe & $3(0.9)$ \\
Metastasis to the kidney & $2(0.6)$ \\
Multilocular clear & $13(3.8)$ \\
Others & \\
& $25(7.4)$ \\
Benign & $14(4.1)$ \\
AML & $11(3.3)$ \\
Others &
\end{tabular}

AML: angiomyoma.

Table 2. Characteristics of 292 patients with PT IaNOMO renal cell carcinoma.

\begin{tabular}{|c|c|c|c|}
\hline & Delayed surgery & Immediate surgery & $p$ value \\
\hline Number of patients & 32 & 260 & \\
\hline Gender & & & n.s. \\
\hline Male & 25 & 187 & \\
\hline Female & 7 & 73 & \\
\hline Age & & & n.s. \\
\hline Median & 643 & 63.7 & \\
\hline Range & $35-80$ & $30-86$ & \\
\hline \multicolumn{4}{|l|}{ Observation period } \\
\hline Mean (month) & 26.2 & - & \\
\hline Range (month) & $6.5-74.8$ & - & \\
\hline Operation method & & & 0.0012 \\
\hline radical nephrectomy & 10 & 161 & \\
\hline partial nephrectomy & 22 & 100 & \\
\hline Histopathological classification & & & n.s. \\
\hline Clear cell carcinoma & 27 & 231 & \\
\hline Non-clear cell carcinoma & 5 & 28 & \\
\hline Unknown & 0 & 2 & \\
\hline \multicolumn{4}{|l|}{ postoperative follow up time } \\
\hline Mean (month) & 39.7 & 51.1 & n.s. \\
\hline
\end{tabular}

n.s.: not significant. 
The 5-year overall survival rate (OSR) was $72.6 \%$ in the delayed surgery group, and $92.2 \%$ in the immediate surgery group (Table 3 ). The cancer-specific 5-year survival rate (CSSR) was $87.5 \%$ in the delayed surgery group, $100 \%$ in the immediate surgery group
(Table 4). The 5-year cancer recurrence-free rate (CRFR) was $96.2 \%$ in the delayed surgery group, and $98.0 \%$ in the immediate surgery group (Table 5). Only CSSR was significantly different between them $(p$ $=0.0002$ ).

Table 3. Overall survival rates: delayed surgery versus immediate surgery.

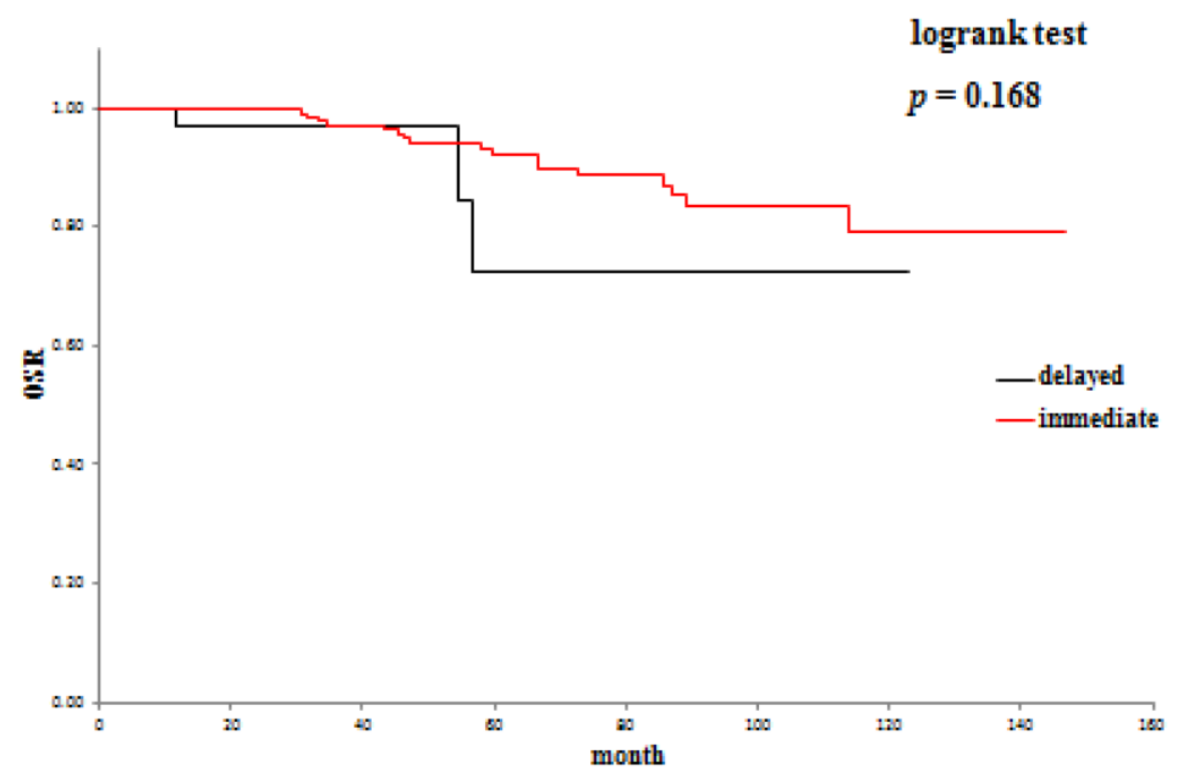

Table 4. Cancer-specific survival rates: delayed surgery versus immediate surgery.

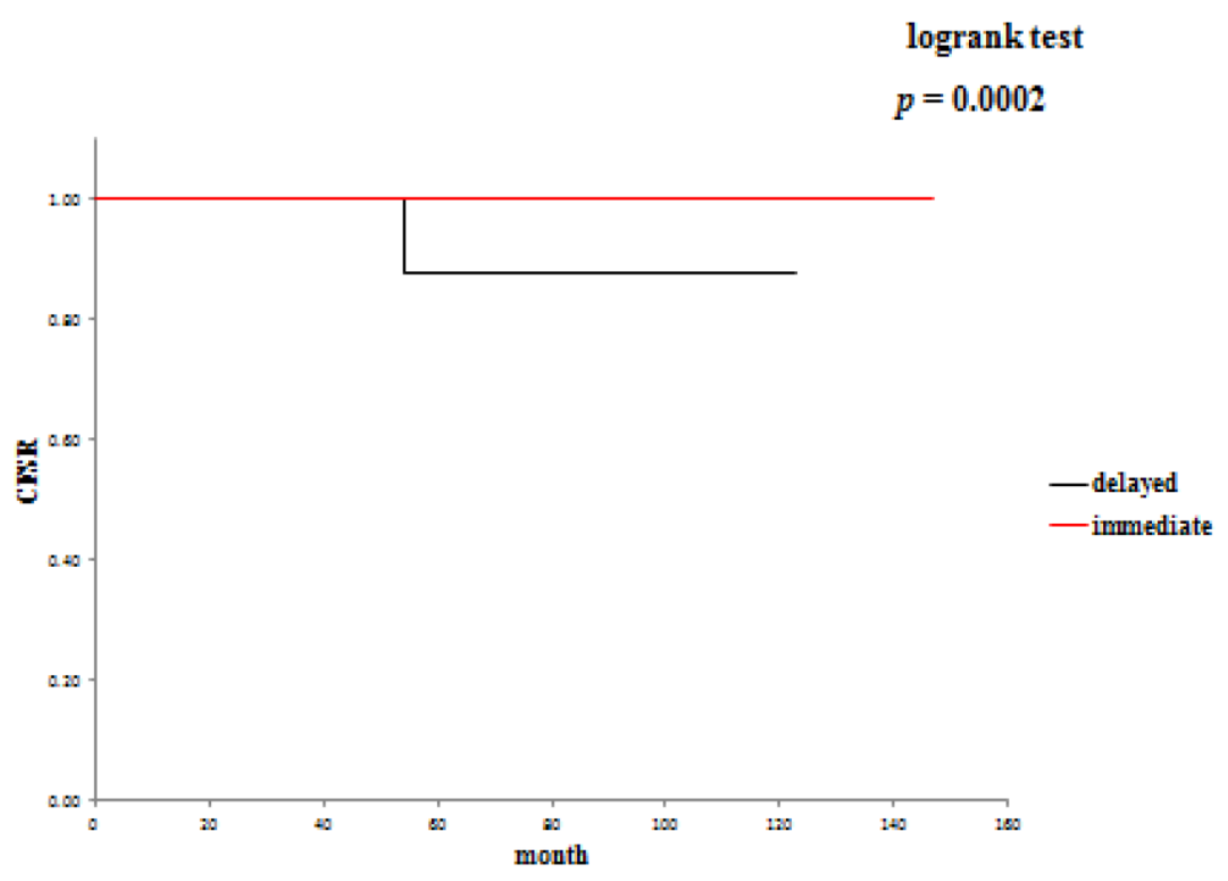


Table 5. Cancer recurrence-free rates: delayed surgery versus immediate surgery.

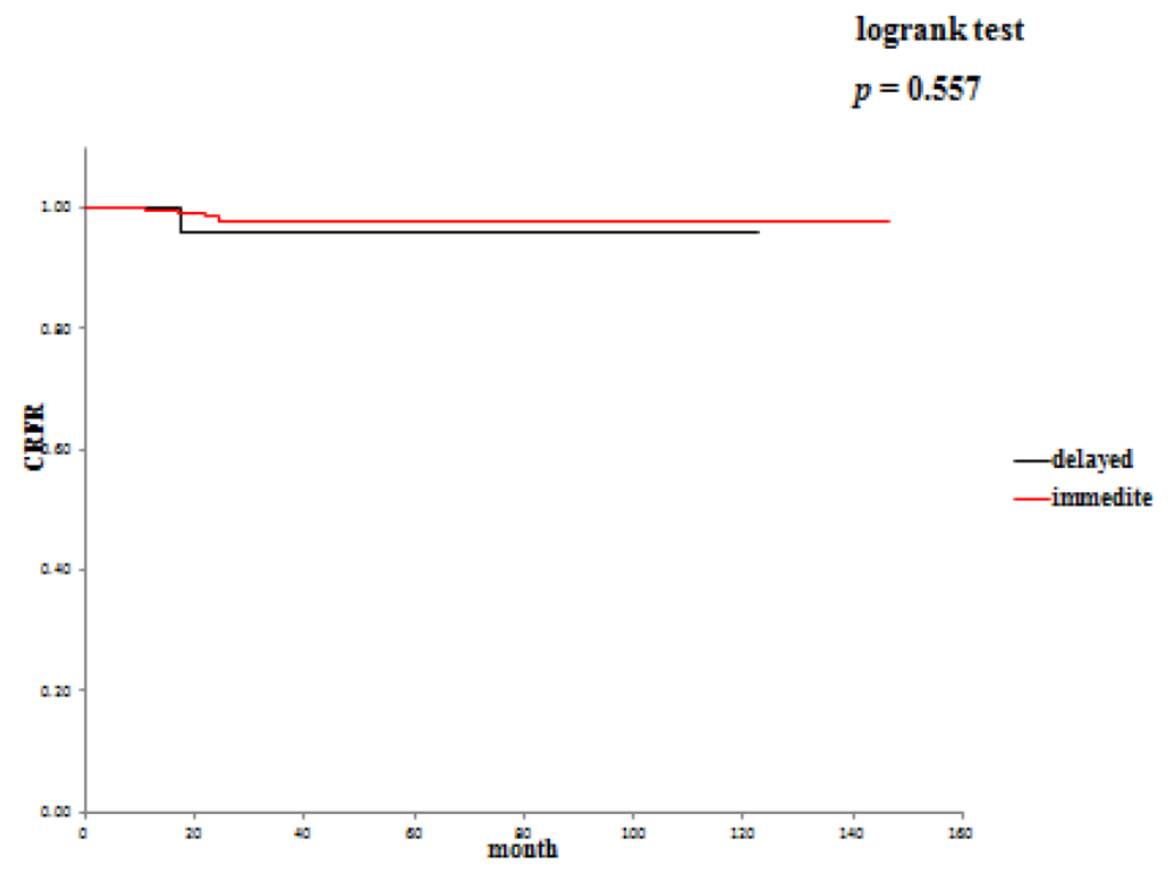

\section{Discussion}

A greater number of small, asymptomatic renal tumors are being incidentally detected nowadays. The good prognosis of incidental RCC is excellent as evidenced by the results of surgery. 8,10

Active surveillance is most commonly considered in early prostate cancer, however, recent advances regarding tumor detection tools such as ultrasound and high speed CT scan, have made surveillance of RCC possible.11-15 Active surveillance is becoming more common, in particular in elderly patients or patients with comorbidities who may not be candidates for surgery. This approach is based on retrospective cohort study of the growth rate and natural history of incidentally detected small renal tumors. ${ }^{14-16}$

Factors to be taken into account for SRM treatment involve tumor size at the time of diagnosis as well as tumor proliferation rate; $55 \%$ to $60 \%$ of SRM are indolent RCC and $20 \%$ to $25 \%$ are progressive RCC. ${ }^{17,18}$ Considering preoperative progression factors, these models allow quantitative detailing of the risks of recurrence, metastasis and survival. However, these tools have several limitations regarding highly qualified treatment decisions in the management of SRM. 16

In general, size is proportionate to the grade of malignancy. ${ }^{19}$ Now then, when should tumors be treated proactively? How big in diameter? In the case of SRM smaller than $1.0 \mathrm{~cm}, 38-46 \%$ are benign. On the other hand, only $6.3-7.1 \%$ are benign for lesions larger than $7.0 \mathrm{~cm} \cdot{ }^{20}$ It has been reported that renal masses $\geqq 3 \mathrm{~cm}$ in diameter have more aggressive potential, resulting in more metastatic cases. ${ }^{21,22}$

Moreover, the preferred nomenclature is growth rate. Renal masses $<2.45 \mathrm{~cm}$ at diagnosis were shown to have an average growth rate of $0.13 \mathrm{~cm} /$ year, while masses $>2.45 \mathrm{~cm}$ had a growth rate of $0.40 \mathrm{~cm} /$ year. ${ }^{15}$ Larger tumors and larger tumor volumes at diagnosis, and at the conclusion of observation tended to progress. Significant differences in both the average growth rate $(0.80 \mathrm{~cm} /$ year vs. $0.3 \mathrm{~cm} /$ year $)$ and the average volumetric growth rate $\left(27.1 \mathrm{~cm}^{3} /\right.$ year vs. $6.2 \mathrm{~cm}^{3} /$ year) have also been observed. ${ }^{23}$

Generally, local recurrence rates of RCC reportedly vary from $0 \%$ to $7 \%$, and disease-specific survival probabilities ranged from $89 \%$ to $100 \% .^{24}$ In our study 34 of 328 patients underwent delayed surgical intervention. In this study, patients with a time to tumor doubling (TTD) of more than six months had a trigger to transit to the operation. As a result, one of 34 patients died of local recurrence. ${ }^{25}$

Active surveillance and delayed surgical intervention of SRMs offers oncological efficacy equivalent to surgery in the short / intermediate term. ${ }^{26,27}$ In our study, the 5-year OSR was 72.6\%, the 5-year CSSR was $87.5 \%$ and the 5-year CRFR was $96.2 \%$ in the delayed intervention group. On the other hand, the 5-year OSR was $79.3 \%$, the 5 -year CSSR was $100 \%$ and the 5 -year CRFR was $98 \%$ in the immediate intervention group. Considering that there was no significant dif- 
ference in OSR between the two groups, it may be reasonable in cases of SRM incidentally detected at diagnosis of another malignancy to treat the diagnosed malignancy first and start the treatment for SRM when the treated malignancy has become relatively stable. It will be necessary to evaluate a large number of such patients to draw conclusions.

In conclusion, because short and intermediate term oncological outcomes of active surveillance and delayed intervention for SRMs are the same, ${ }^{27}$ active surveillance including delayed intervention surgery for small renal cell carcinoma may be considered a useful strategy by more institutions and become a treatment option in the future. Future investigations and development of molecular and histologic markers of disease progression are needed, as well as randomized clinical trials to investigate the efficacy of active surveillance and delayed surgery management. Accumulation of such data may contribute to future management of SRMs.

\section{Competing Interests} work.

The authors report no conflicts of interest in this

\section{References}

1. Wunderlich H, Schumann S, Jantitzky V, et al. Increase of renal cell carcinoma incidence in central Europe. Eur Urol. 1998; 33(6): 538-41.

2. Chow WH, Devesa SS, Warren JL, et al. Rising incidence of renal cell cancer in the United States. JAMA. 1999; 281(17): 1628-31.

3. Hock LM, Lynch J, Balaji KC. Increasing incidence of all stages of kidney cancer in the last 2 decades in the United States: an analysis of surveillance, epidemiology and end results program data. J Urol. 2002; 167(1): 57-60.

4. Lightfoot N, Conlon M, Kreiger N, et al. Impact of noninvasive imaging on increased incidental detection of renal cell carcinoma. Eur Urol. 2000; 37(5): 521-7.

5. Siemer S, Uder M, Humke U, et al. Value of ultrasound in early diagnosis of renal cell carcinoma. Urologe A. 2000; 39(2): 149-53.

6. Chawla SN, Crispen PL, Hanlon AL, et al. The natural history of observed enhancing renal masses: meta-analysis and review of the world literature. J Urol. 2006; 175(2): 425-31.

7. Klatte T, Patard JJ, de Martino M, et al. Tumor size dose not predict of metastatic disease or prognosis of small cell carcinomas. J Urol. 2008; 179(5): 1719-26

8. Kunkle DA, Egleston BL, Uzzo RG. Excise, ablate or obseve: the small renal mass dilemma - a meta - analysis and review. J Urol 2008; 179: 1227-33.

9. Sobin LH, Gospodarowicz MK, Wittekind Ch. TMN Classification of malignant tumours 7th ed. Oxford, UK: Wiley-Blackwell; 2009.

10. Hafez KS, Fergany AF, Novick AC. Nephron sparing surgery for localized renal cell carcinoma: impact of tumor size on patient survival, tumor recurrence and TNM staging. J Urol. 1999; 162(6): 1930-3.

11. Crispen PL, Wong YN, Greenberg RE, et al. Predicting growth of solid renal masses under active surveillance. Urol Oncol. 2008; 26(5): 555-9.

12. Kunkle DA, Crispen PL, Chen DY, et al. Enhancing renal masses with zero net growth during active surveillance. J Urol. 2007; 177(3): 849-53.

13. Heuer R, Gill IS, Guazzoni G, et al. A critical analysis of the actual role of minimally invasive surgery and active surveillance for kidney cancer. Eur Urol. 2010; 57(2): 223-32.

14. Jewett MA, Mattar K, Basiuk J, et al. Active surveillance of small renal masses: progression patterns of early stage kidney cancer. Eur Urol. 2011; 60(1): 39-44.

15. Mason RJ, Abdolell M, Trottier $G$, et al. Growth kinetics of renal masses: analysis of a prospective cohort of patients undergoing active surveillance. Eur Urol. 2011; 59(5): 863-7.
16. Kim SP, Thompson RH. Approach to the small renal mass: to treat or not to treat. Urol Clin North Am. 2012; 39(2): 171-9.

17. Raj GV, Thompson RH, Leibovich BC, et al. Preoperative nomogram predicting 12-year probability of metastatic renal cancer. J Urol. 2008; 179(6): 2146-51.

18. Karakiewicz PI, Suardi N, Capitanio U, et al. A preoperative prognostic model for patients treated with nephrectomy for renal cell carcinoma. Eur Urol. 2009; 55(2): 287-95.

19. Schlomer B, Figenshau RS, Yan Y, et al. Pathological features of renal neoplasms classified by size and symptomatology. J Urol. 2006; 176(4 Pt 1): $1317-20$

20. Frank I, Blute ML, Cheville JC, et al. Solid renal tumors: an analysis of pathological features related to tumor size. J Urol. 2003; 170(6 Pt 1): 2217-20.

21. Remzi M, Ozsoy M, Klingler HC, et al. Are small renal tumors harmless? Analysis of histopathological features according to tumors $4 \mathrm{~cm}$ or less in diameter. J Urol. 2006; 176(3): 896-9.

22. Lane BR, Tobert CM, Riedinger CB. Growth kinetics and active surveillance for small renal masses. Curr Opin Urol. 2012; 22(5): 353-9.

23. Smaldone MC, Kutikov A, Eqleston BL, et al. Small renal masses progressing to metastases under active surveillance: a systematic review and pooled analysis. Cancer. 2012; 118(4): 997-1006.

24. Lam JS, Shvarts O, Pantuck AJ. Changing concepts in the surgical management of renal cell carcinoma. Eur Urol. 2004; 45(6): 692-705.

25. Sugimoto K, Shimizu N, Oki T, et al. Clinical outcome of incidentally discovered small renal cell carcinoma after delayed surgery. Cancer Manag Res. 2013; 5: 85-9.

26. Rais-Bahrami S, Guzzo TJ, Jarrett TW, et al. Incidentally discovered renal masses: oncological and perioperative outcomes in patients with delayed surgical intervention. BJU Int. 2009; 103(10): 1355-8.

27. Patel N, Cranston D, Akhtar MZ, et al. Active surveillance of small renal masses offers short-term oncological efficacy to radical and partial nephrectomy. BJU Int. 2012; 110(9): 1270-5. 